\title{
Work -Life Balance of Females in Corporate Culture while Working from Home during Pandemic: Experiences and Coping Strategies
}

\section{Joshi R ${ }^{1}$, Birdi AK ${ }^{2}$ and Panchal S $^{3 *}$}

${ }^{1}$ Assistant Professor, Amity University Rajasthan, India

${ }^{2}$ Senior Academician, Researcher, Life Coach, India

${ }^{3}$ Assistant Professor, Department of Psychology, Rajiv Gandhi University, India

*Corresponding author: Sandeep Panchal, Assistant Professor, Department of Psychology, Rajiv Gandhi University (A Central University), Doimukh, Itanagar, Arunachal Pradesh, India, Email: sandeep.panchal@rgu.ac.in

\section{Research Article \\ Volume 5 Issue 2}

Received Date: December 06, 2021

Published Date: December 28, 2021

DOI: $10.23880 / \mathrm{mhrij}-16000157$

\section{Abstract}

The purpose of the present study was to examine the lived experiences and coping strategies of Female Managers and Executives in corporate Culture while working from home during Pandemic. Semi-structured interviews were conducted with 25 women who were Middle level executives and Managers working for various branches of Service Industry ranging from Insurance sector, Banking Sector, Finance and Investment sector etc. A phenomenological methodology was used to uncover the lived experiences of these women while working from home, looking after families that included Spouse, Children and Elderly. These women were chasing deadlines, attending online meetings simultaneously fixing meals, ensuring children attend online classes and looking after other family members. The work shift extended till late at night with little or no help in household chores. Results yielded that these women were extremely stressed; the work- life balance went for toss. Dual role perfectionism expected by them both from others as well as self resulted in stress, anxiety, physical and mental fatigue, adverse effect on physical and mental health as well as lowering of self- efficacy and self-esteem. Coping strategies included religion and spirituality, delegation of work and shedding unrealistic expectations, support networks, mentorship, and selfcare. Directions for future research, clinical and theoretical implications of experiences of results of unrealistic expectations, lack of work -life balance are being discussed.

Keywords: Work-Life Balance; Stress; Anxiety; Unrealistic Expectations; Self-Care

\section{Introduction}

In November 2019, discovery of first ever case of novel virus set unprecedented events in action hitherto unheard of in personal and professional lives of people across the globe. The lockdowns imposed across the globe to check spread of infection resulted in work force diverted to home instead of office premises. Work from Home (WFH) is currently known as an alternative working mode to minimize the risk of COVID-19 infection. However, WFH is not new and has been brought to the attention of several schools of thought for many years. The WFH concept was initially mentioned by Nilles JM [1] dating back to 1973, known as "telecommuting" or "telework" [2]. WFH has been defined in various terms over 


\section{Mental Health \& Human Resilience International Journal}

the four decades, namely remote work, flexible workplace, telework, telecommuting, e-working. These terms refer to the ability of employees to work in flexible workplaces, especially at home, by using technology execute work duties [3].

There are a number of Studies and Researches that highlight the pros and cons of the working from home that includes time saved in commuting, flexible working hours, more time for family [4]. However other studies that suggest about flip side of working from home such as mental fatigue, distractions, anxiety, worries, procrastination etc $[2,5]$. Number of families where both partners work has increased significantly in India owing to women receiving higher education has seen a significant increase over last 5 years, the Gross Enrolment ratio of female students has increased by $18 \%$ [6]. Even though women ventured outside to earn a livelihood and establish a career for themselves, the traditional role prescribed for them tends to pull them in two opposing directions. There by affecting them mentally, physically and emotionally.

A number of families where women are working, whether joint or nuclear, mostly onus of house holds responsibilities and chores are shouldered by women. They are responsible for fixing meals for the family before they leave for work, attend to cleaning, laundering and look after needs of children and elderly, failing which they are burdened with guilt and feelings of inefficiency. A lack of work- life balance among women often results in anxiety, depression, sleep difficulties, lack of confidence, feelings of worthlessness, helplessness, loss of drive and false positives that tend to affect the mental health adversely [7-9]. A numbers of factors has been studies by the researchers to mental health professional at workplace, psychological factors general health problems, negative effects [10], alcohols uses among professionals [11], occupational stress and work family conflicts in sample of police professionals [12], type a behaviour and burnout [13], workplace and mental health problems [14], stress levels and burnout, work environment, stress and mental health [15], And Psychological Distress, Negative Affect, Daily Stress, Suicidal Ideation and Mental Health [16] . The present study is aimed to uncover a deeper understanding of lived experiences of middle level Executives and Managers working from home during Pandemic along with coping strategies employed by them.

\section{Methods}

\section{Participants}

Participants were 25 Middle level Executives and Managers with an age range from 35 to 50 years, and majority of participants falling between 35- 42 years drawn from Rajasthan, New Delhi and Mumbai respectively. All of them were working for at least last 5 years in sectors like Banking, insurance, finance and investment. All had at least Bachelor's degree, with majority of them having done an M.B.A. and lived with their families, by birth or after marriage.

\section{Sources of Data}

Participants undertook a brief demographic questionnaire along with a semi-structured interview schedule based on two research questions was developed to gain a deeper understanding of participants lived experiences of working from home.

\section{Research Questions}

- What are participant's experiences while working from home? Whether positive or negative?

- What coping strategies were employed by them in case of negative experiences and reinforcing mechanism in case of positive experiences?

\section{Procedures}

Participants were selected through purposive sampling after obtaining informed written consent voluntarily, without any compensation. The primary investigator conducted indepth, audio-taped, semi-structured interviews in private rooms and transcripts were obtained.

\section{Data Analysis}

The transcripts were reviewed and analysed after each interview to attain greater insight and meaning. All the significant, repetitive, relevant and non-overlapping statements about participants experiences about working from home were recorded. These statements were then clustered into themes. These themes were further employed to provide clear picture of what participants experienced about the topic.

\section{Results}

On the basis of analysis of statements, 4 themes for experiences while working from home were extractedExperiencing stress and anxiety due to lack of work life balance, Physical and Mental Fatigue and feelings of low self -esteem and self- efficacy [17]. Similarly four themes from coping strategies emerged that included- turning to religion and spirituality, delegation of work and shedding unrealistic expectations, support networks, and mentorship, and selfcare. 


\section{Mental Health \& Human Resilience International Journal}

\section{Experiencing Anxiety and Stress}

The participants reported experiencing anxiety and stress while they worked from home. Their professional roles were demanding and required lot of time and focus. Almost every participant found herself crunched for time micromanaging household chores and attending professional demands. The lock down that was imposed to restrict spread of infection also resulted in restriction of movement. Before lockdown professionals, students and everyone had their routines set, availability of house help for cooking, cleaning, laundering made life easier for everyone, especially for participants as they were able to delegate their work to house help and only managed them. This left them with much time to attend to their professional and personal obligations. However post lockdown, the ecstasy of working from home vanished within a few days when they realized that they were without help on their own. The household chores with the constant phone calls, beeps of notifications for messages and mails made them restless. Most of them descried the experience as stressful and anxiety provoking. They were almost always engaged with something or the other, striking off chores from to do list, shooting an urgent mail, fixing a snack for elderly to attending online Parent Teacher Meeting. All of this left them much exhausted, not able to find out time for self-care, uneven times for meals, not getting enough sleep, loosing or gaining weight without conscious effort along with experiencing feelings of restlessness and irritation. Most of these symptoms include the Hurried Woman Syndrome symptoms, the term first coined by Dr. Brent Bost who maintained that it tends to effect women broadly from age group between 25-55 are affected the most who try to do many things in a short period of time. Following are illustrative quotes.

"The charm of WFH faded during last one year. It was supposed to give us more time with our families, to be more productive, to learn new skills. It all ended up waking 2 hours early to cook breakfast, followed by lunch and laundry to be able to sit at 9 in front of laptop without feeing stressed"

"Demands of family members, boss, colleagues seems never ending. I cannot eat, sleep without distractions. I sleep light, waking up number of times to check if I overslept and need to depend on black coffee throughout the day to remain active"

"I feel like 24 hours are not sufficient. The continuous notification beeps of mails and messages, constant nagging of children, expectations from family for cooking something exotic, because I have so much time now that I am working from home, drive me crazy. I often have to exert control to not snap and shout"

\section{Mental and Physical Fatigue}

While Offices assumed that WFH facility cut down on travelling time and flexibility of working anytime and virtual mode made it easier to connect, number of online engagements has increased tremendously. There are online meetings, reviews, and get together, farewells that are conducted and stretched well beyond time. Continuous online attendance tends to strain eyes, uneasiness and pain in muscles, especially back aches. Lack of availability of house help, even after lockdowns were lifted for fear of infection made the days turn tedious and tiresome because of chores. Most participants felt by end of the day they were exhausted; physically as well mentally. To illustrate a few quotes are as follows"

"Attending online meeting writing and answering mails continuously, my eyes were strained and a constant headache made me see a doctor. I now have prescription glasses"

"Easy connectivity has its pros and cons. On a positive note, virtual platform makes meeting convenient, on the other hand meeting and performance reviews make one after another are extremely tiring."

"I am literally surviving on coffee. After house hold chores, Parent Teacher meetings, paying bills, spending time with kids and in -laws and shooting that last mail, I crave for a cup of strong black coffee more than a good night's sleep"

\section{Experiencing Low Self -Esteem, Self-Efficacy and Guilt}

The constant flow of work; personal and professional left the participants trying their best to fulfil both roles. However lack of time and resources often made them overlook, forget or hastily complete a task. These mistakes made them or forgetfulness made them doubt their abilities, expertise and their intentions. Lack of self -care in terms of proper nutrition, sleep, exercise and grooming made them view their self- concept and body image in negative light. Some quotes to illustrate the same are as follows:

"I have gained 3 kilos in last 7 months, My hair are dry coarse and lifeless and black circles under eyes. I do not feel like looking at myself in mirror. Like so many mothers don't have time for cooking healthy so I give my children packaged snacks much to displeasure of my in-laws"

"I feel like an imposter. I head the finances department, and I make mistakes in handling money matters of my own house. Then, there were so many glitches in my reports. My Reporting officer was so mad. I feel so incompetent"

"By the end of day I just wish to lie down at stare into space. The thought of physical intimacy with my partner is not even bearable. He gets angry, and rightly enough but I am physically, mentally and emotionally so exhausted that even if I engage, it's mostly going through motions" 


\section{Mental Health \& Human Resilience International Journal}

\section{Process: Reaction to Anxiety, Stress, Physical and Mental Fatigue and feelings of Low Self- Esteem, Self-Efficacy}

Cognitive reactions to the anxiety, stress, physical, mental fatigue and feelings of low self-esteem, self- efficacy were varied among participants. Many of them experienced the Fight or flight situation and were overwhelmed by the same. Most of them thought the situation was out of control because of their own short comings. They indulged in selfblame and self -pity. They considered self- care as last priority and focused all their energy and efforts to successfully complete responsibilities as well as demands at professional and personal front single handed, not delegating work to others; especially at personal front.

They blamed themselves if things went bad and felt guilty and doubted their abilities. The lack of cooperation by family members or by colleagues was not questioned, rather they accepted all demands without explaining how it impacted their overall well -being. They experienced low self-esteem and feelings of inefficacy [18]. They compensated of their perceived lack of efficiency by putting in more efforts to keep family members and colleagues content and happy exerting themselves further thereby starting the vicious cycle. There was also a fear of job security as economies across the world were sinking and lays offs were becoming frequent. Some of the participants were primary bread winners, it was they therefore invested more energy and efforts to complete the deadlines and prove themselves of more value compared to others.

"If I refused to attend an online meeting at last hour, I would later feel guilty and end up taking up extra work till late at night."

"There is always a fear, fear of your name appearing in the list of people for lay -off. I make it a point to deliver before deadline, always proactive. Juggling buying medicines for my mother to replying to mails, it is like always walking on a tight rope"

\section{Coping Strategies}

Coping with Religion and Spirituality: Religion and Spirituality played an important role in enhancing over all wellbeing of the participants. An impressive repertoire of research suggests how Religion and spirituality improves subjective wellbeing, enhances positive emotions as well as boosts physical and mental health [13]._Most of the participants relied on praying and seeking refuge in spirituality when faced with situations that were stressing as well as anxiety -provoking and reported feeling better. The ones who engaged in rituals pertaining to their respective religions reported better subjective wellbeing as compared to those who did not. Mindfulness and meditation's effect on subjective well- being along with increased physical and mental health has been well documented in a number of studies. Participants who engaged in meditation reported feelings of calmness and improved focus and rigour [15].

Coping with Delegation of Work \& Shedding Unrealistic Expectations: The strategy of delegation of work was specifically found to be useful in personal life. Most of the participants had distorted view of a successful woman who would perfectly manage the Work Life Balance with no efforts or stress. To them a successful woman was one whose house was spick and span, children neat, tidy, healthy excelling in academics and extracurricular activities, family members smiling with content and joy in a picture perfect frame, Work Assignments, deadlines, targets before time and all official correspondence answered. And all of this without helps. This unrealistic approach did not match with the reality where house would sometimes be untidy and messy, children eating junk food occasionally and missing a few meetings or delayed replies to mails. In course of time as WFH extended, they felt the need to overlook perfectionism and delegating some of the chores to other family members even if it was met with resistance and some resentment.

"As work from Office seemed to take forever, I had to call my cook and cleaner with appropriate precaution and safety measures much to chagrin of some of my family members. I had to do so to maintain my sanity"

"I set a boundary for my bosses and Colleagues. I refused to answer official calls after 8 and did not look at official mails after 7, unless there was an emergency. My professionalism was questioned at first, but I held my ground. I had to do it for my mental peace and physical health"

Support System: One of the most effective means of overcoming stress anxiety and feelings of guilt was looking for a support system, which could be a friend, spouse, colleague or a mentor. The participants who sought refuse in support system talked about their problems, their challenges and how they felt about it. When they confided in their support system, it served the purpose of Catharsis in a similar manner as happens during counselling and therapies between therapist or counsellor and client where the client is heard without any without any judgement or interruption.

Story Telling as a technique is widely employed and accepted in field of Positive Psychology. Positive psychology research suggests that narrating a painful experience actually help in releasing stress and gaining resilience.

"My mother is my best friend, when I feel completely trapped its her I turn to for counsel. She is the best counsellor in the world"

"At verge of burn -out I called my boss to put in my papers. She heard me patiently and provided practical solutions to my 


\section{Mental Health \& Human Resilience International Journal}

problems. I think I should have done that before"

"My Husband understands me like no one. If it weren't for him;

I would have never reached where I am. My job role is very demanding and at times I feel, I just can't go any further. He hears me out. That is more then enough, he hears me out"

\section{Discussion}

The study aims to assess and give voice to lived experiences of females in Middle level working in corporate culture. What kind of experiences them while working from home, what coping strategies were used by them to counter and deal with negative experiences and how they reinforced the positive ones? The finding that keeping realistic expectations, making self-care a priority by engaging in activities that promote relaxation and developing a support system that acts as cushion during tough times. Work from Home may continue for a long time to come, with some Organizations even considering shutting premises for good .Circumstances like that families where females take care of professional and personal front have set healthy boundaries for themselves to avoid stress, anxiety and other mental health issues. Despite so expiring so much agony, none of the participants sought Counselling or tried to contact Mental Health Professionals for help. The implications of the study are relevant for at both individual as well as Organizational level. Organizations must ensure that over all wellbeing of employees is of utmost importance as they human resources are more valuable resources. Over burden of work load may result in demotivation, lack of moral, anxiety, distress, burn out and other mental health issues which may also include serious ones such as self-harming and suicidal tendencies. Further Research is needed to investigate and examine the complexities of experiences of females working in corporate culture managing work and family to initiate and encourage practices to enhance their physical, mental, social, psychological and emotional health.

\section{Future Implications}

The world was taken by surprise when the Pandemic hit with everyone unprepared for it. Neither employees nor, employers had plans for carrying on duties smoothly. Trial and error took considerable time and energy for everyone to reach feasible and mutually beneficial decisions. The implications of the study are relevant for at both individual as well as Organizational level. Organizations must ensure that overall well-being of employees is of utmost importance as they human resources are more valuable resources. Over burden of work load may result in demotivation, lack of moral, anxiety, distress, burn out and other mental health issues which may also include serious ones such as selfharming and suicidal tendencies. Further Research is needed to investigate and examine the complexities of experiences of females working in corporate culture managing work and family to initiate and encourage practices to enhance their physical, mental, social, psychological and emotional health. There is a serious need for appointment of mental health Professionals in Corporates as well since there is a serious dearth mental health awareness and knowledge, especially related to removal of stigma associated with seeking help. A combined effort from at all levels of leadership, at Organizational and personal level, at professional and personal level to address and streamlining mental health issues, to be open to dialogs for uncomfortable situations and normalizing seeking help will ensure that all stakeholders are at a win-win situation and help in achieving the delicate work life balance, irrespective of mode of operation, online or offline.

\section{References}

1. Nilles JM (1988) Traffic Reduction by Telecommuting: A Status Review and Selected Bibliography. Transportation Research Part A: General 22(4): 301-317.

2. Messenger JC, Gschwind L (2016) Three Generations of Telework: New ICTs and the (R) Evolution from Home Office to Virtual Office. New Technology, Work and Employment 31(3): 195-208.

3. Gajendran RS, Harrison DA (2007) The Good, the Bad, and the Unknown About Telecommuting: Meta-Analysis of Psychological Mediators and Individual Consequences. J Appl Psychol 92(6): 1524-1541.

4. Delanoeije J, Verbruggen M, Germeys L (2020) Boundary role transitions: A day-to-day approach to explain the effects of home-based telework on work-to-home conflict and home-to-work conflict. Human Relations 72(12): 1843-1868.

5. Fan W, Lam J, Moen P (2019) Stress Proliferation? Precarity and Work-Family Conflict at the Intersection of Gender and Household Income. Journal of Family Issues 40(18): 2751-2773.

6. Gohain M (2021) 18\% More Women in Higher Education in 5 years. Times of India.

7. Kinman G, Jones F (2008) A life beyond work? Job demands, work life balance, and wellbeing in UK academics. Journal of Human Behaviour in the Social Environment 17(1-2): 41-60.

8. Aryee S, Srinivas ES, Tan HH (2005) Rhythms of life: antecedents and outcomes of work-family balance in employed parents. J Appl Psychol 90(1): 132-146.

9. Agarwal R, Mishra AK, Dixit P (2015) Gender and work 


\section{Mental Health \& Human Resilience International Journal}

life balance. International Journal of Science Technology and Management 4(1): 57-65.

10. Panchal S, Joshi HL (2021) Predictors of Suicidal Ideation among Married Professionals: General Health Problems and Negative Affect. Journal of Clinical Psychology and Mental Health Care 3(3): 1-5.

11. Panchal S, Joshi HL (2021) Mental Health Problems and Alcohol Use among Professionals. Asean Journal of Psychiatry 22(1): 1-5.

12. Sharma P, Panchal S, Pal S (2020) Occupational Stress and Work-Family Conflict among Police Constables. The International Journal of Indian Psychology 8(4): 327335.

13. Sharma P, Panchal S, Pal S (2020) Burnout and Type a behaviour among Police Constables: A Comparative Study. The International Journal of Indian Psychology 8(4): 548-554.
14. Panchal S, Joshi HL (2020) Mental Health Problems at Workplace: A review. The International Journal of Indian Psychology 8(3): 525-528.

15. Kumar U, Joshi HL, Panchal S, (2015) Role of Work Environment in Stress and Mental Health. Journal of Research: The Bede Athenaeum 6(1): 98-103.

16. Panchal S, Joshi HL (2016) An Investigation of Psychological Distress, Negative Affect, Daily Stress, Suicidal Ideation and Mental Health among Married Professionals: A Comparative Study. Indian Journal of Psychological Science 6(2): 095-106.

17. Sharma P, Panchal S, Pal S (2021) Gender Differences in Stress Symptoms and Burnout among Police Constables. J Psychol Psychother 11: 415.

18. Messenger J, Llave OV, Gschwind L, Boehmer S, Vermeylen G, et al. (2017) Working Anytime, Anywhere: The Effects on the World of Work. Eurofound pp: 1-80. 